\title{
MICROSTRUCTURE AND PROPERTIES OF Ni-Fe BASE Ta-718
}

\author{
Scott A. Loewenkamp and John F. Radavich \\ School of Materials Engineering \\ Purdue University, W. Lafayette, IN 47907 \\ Tom Kelly \\ General Electric Co \\ Cincinnati, OH 45215
}

\begin{abstract}
The $\mathrm{Nb}$ was replaced by $\mathrm{Ta}$ on a one to one atom basis in alloy 718 . Structural studies show that on solidification the MC, Laves, $\delta$, and $\gamma^{\prime \prime}$ phases which formed are similar to the corresponding phases in cast alloy 718. However, less Laves and $\delta$ phases form on solidification and homogenization occurs at a lower temperature in a shorter time than in cast alloy 718.

The $\gamma^{\prime \prime}$ phase in TA 718 is stable up to temperatures of $1850^{\circ} \mathrm{F}$ which is higher than in alloy 718. The $\gamma^{\prime \prime}$ to $\delta$ transition has not been observed in the normal heat treatments used in this study.

Cast TA 718 possesses tensile and stress-rupture properties as good as cast alloy 718. However, the heat treatments used in the test program are not necessarily optimum for this alloy.
\end{abstract}




\section{INTRODUCTION}

Cast alloy 718 has been used in many gas turbine applications because of its good castability, good weldability, and low cost. However, due to the high $\mathrm{Nb}$ content, as-cast components of alloy 718 become highly segregated during solidification requiring long homogenization cycles which affect weldability. Highly segregated areas tend to show excessive porosity which must be closed by HIP treatments. Current trends for greater $\mathrm{Nb}$ contents for higher strength means greater segregation will form and homogenization may not be achieved. Chemical segregation in alloy 718 produces variation in the precipitation of $\delta, \gamma^{\prime \prime}$ and $\gamma^{\prime}$ phases which leads to differential overaging during engine exposure.

Recent studies of the effects of $\mathrm{Ta}$ in $\mathrm{Ni}$ base superalloys have shown that $\mathrm{Ta}$ stabilizes phases such as $\mathrm{MC}$ and $\gamma^{\prime}$ more than $\mathrm{Nb}$. Little is known of the role of Ta as comparcd to $\mathrm{Nb}$ in 718 type alloys. To study the role of $\mathrm{Ta}$ on segregation and phase stability in 718 type alloys, $\mathrm{Ta}$ was substituted for $\mathrm{Nb}$ on an atom for atom. basis. (Table 1) This alloy is called TA 718. While Ta and Nb are crystallographically similar and would be expected to form the same phases, it is believed that Ta might not produce the same amount of segregation as $\mathrm{Nb}$. A lower tendency for segregation would then allow shorter homogenization cycles, produce high mechanical properties at higher operating temperatures and improve weldability.

\section{MATERIALS AND PROCEDURE}

The material for this study was conventionally cast into $1 / 4$ inch thick plates. A number of the plates were cut into samples for a time-temperature study to determine the solvus behavior of the cast structures. Select samples were then given a $1600^{\circ} \mathrm{F} 1$ hour heat treatment to determine residual segregation remaining after the various solution temperatures.

Other plates of the TA 718 were used for tensile and stress-rupture testing after being HIPped at $2050^{\circ} \mathrm{F} / 14.7 \mathrm{Ksi} / 3 \mathrm{hrs}$. Based on alloy $718 \mathrm{data}$, two post $\mathrm{HIP}$ heat treatments were given to the test bars: Heat treatment $\mathrm{A}$ was $1925^{\circ} \mathrm{F} / 1 \mathrm{hr}$. + $1350^{\circ} \mathrm{F} / 8 \mathrm{hrs}$. $+1150^{\circ} \mathrm{F} / 8 \mathrm{hrs}$. while heat treatment $\mathrm{B}$ consisted of $2000^{\circ} \mathrm{F} / 1 \mathrm{hr}$. + $1500^{\circ} \mathrm{F} / 1 \mathrm{hr} .+1400^{\circ} \mathrm{F} / 2 \mathrm{hrs}$.

Microstructural characterization was carried out using optical and scanning electron microscopy. Chemical analyses were carricd out using EDAX type X-ray analyses on many structural features. Phase extractions were completed using a $15 \%$ HCl and $85 \%$ Methanol solution. A 5 volt potential was applied for 1 and $3 / 4$ hours. Phase identification was then completed using X-ray diffraction patterns from the extracted residues.

Standard room temperature, $1200^{\circ} \mathrm{F}$, and $1300^{\circ} \mathrm{F}$ tensile tests were run while stress-rupture tests were carried out at $1200^{\circ} \mathrm{F}$ and $1300^{\circ} \mathrm{F}$ at $90 \mathrm{Ksi}$.

\section{RESULTS}

\section{$\underline{\text { Structural Study }}$}

Examination of the as-cast material reveals a prominent dendritic solidification pattern containing many carbides in the interdendritic regions as well as Laves and $\delta$ phases, Figure 1. Higher magnifications show the presence of $\gamma^{\prime \prime}$ and $\gamma^{\prime}$ in the interdendritic regions, Figure 2. Chemical analyses show the interdendritic regions to be high in $\mathrm{Ta}$ and $\mathrm{Ti}$ but have reduced levels of $\mathrm{Fe}, \mathrm{Cr}$, and $\mathrm{Ni}$ relative to the dendrites. 

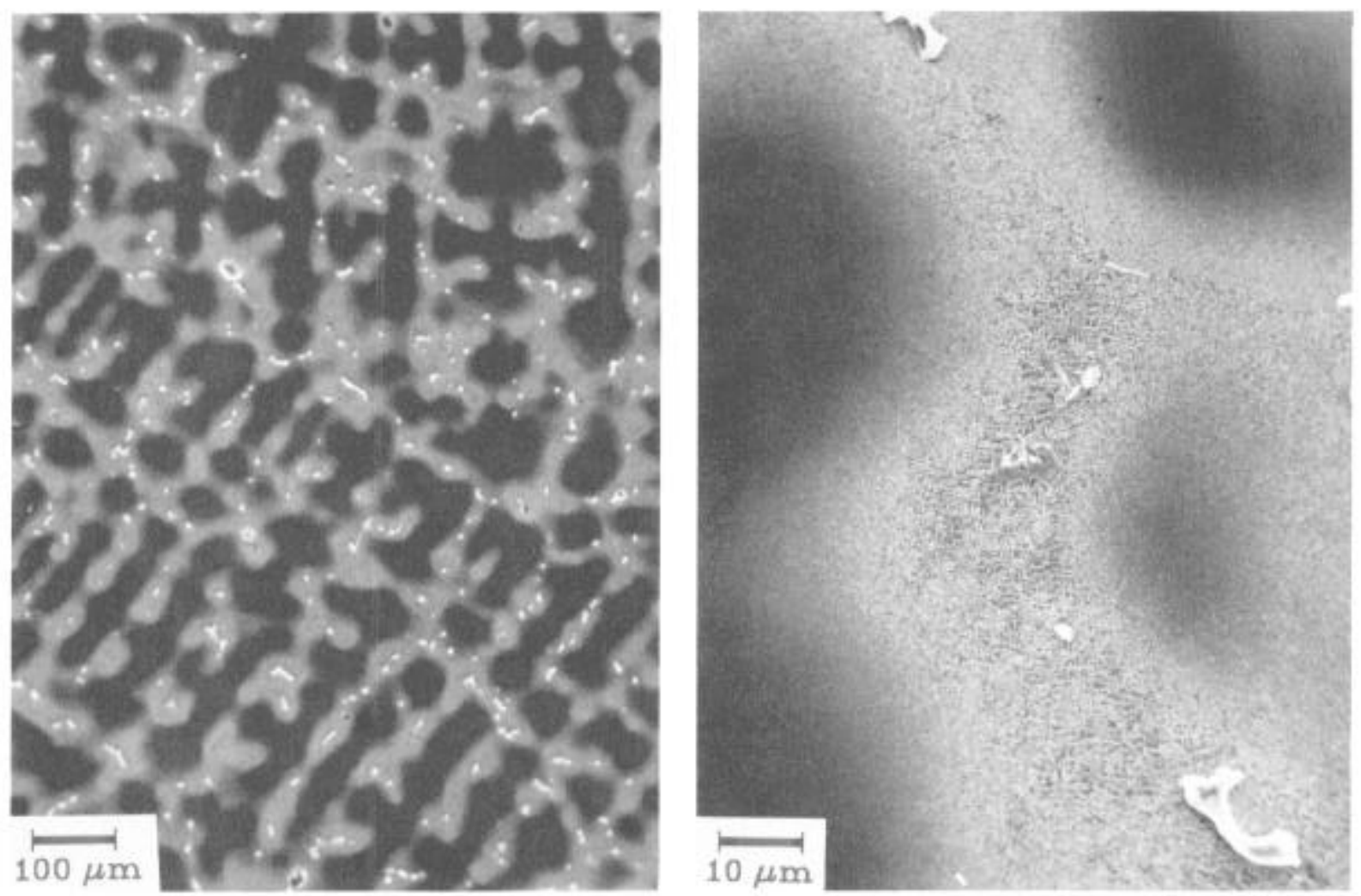

Fig. 1. TA-718 As Cast.

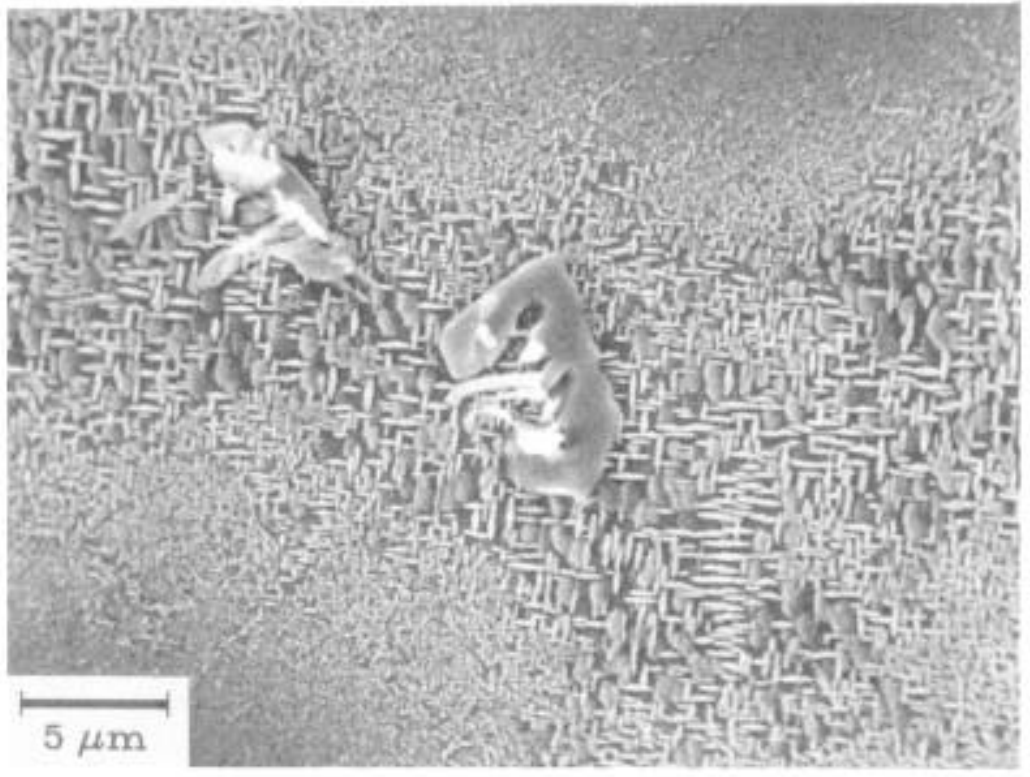



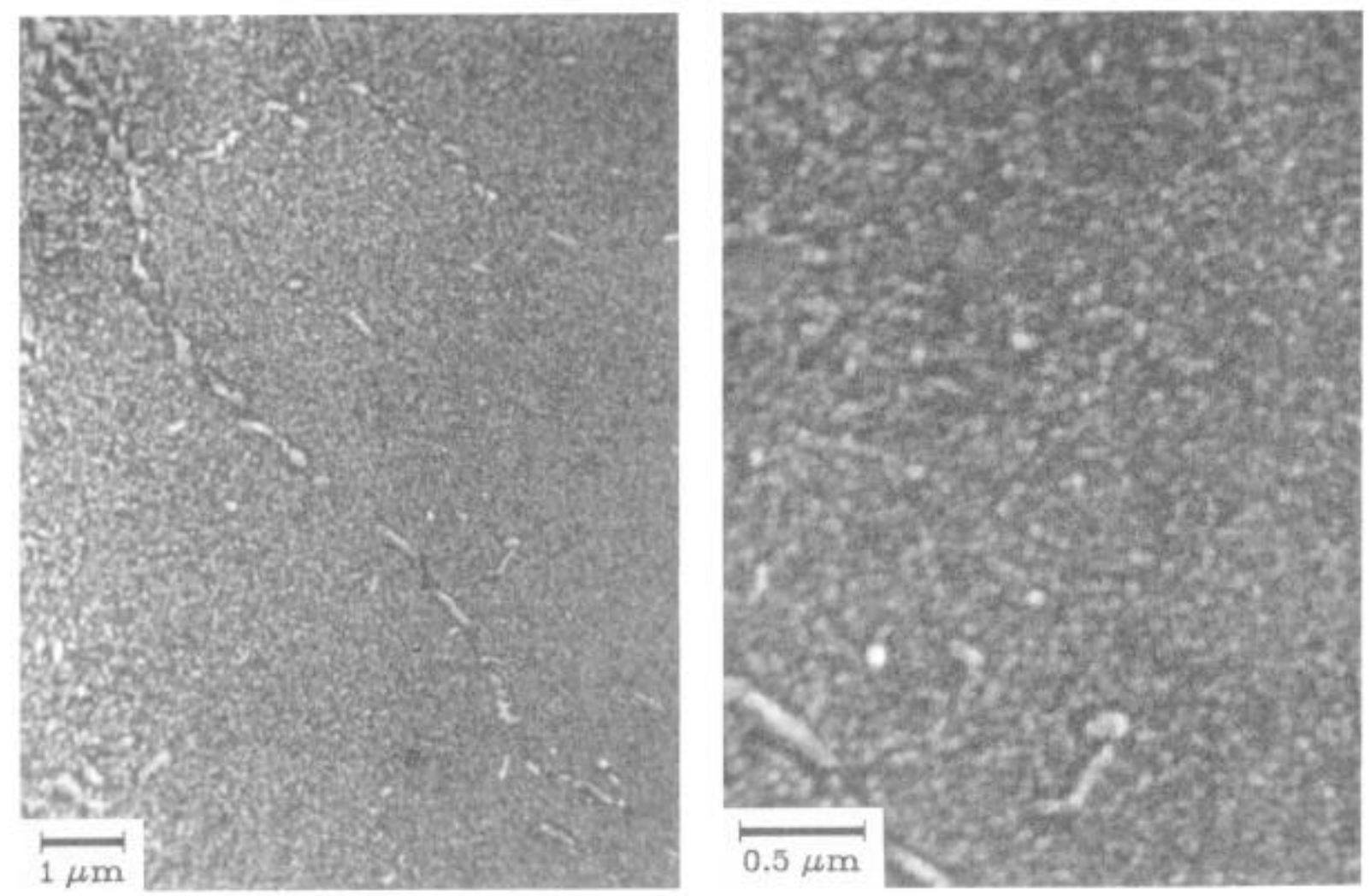

Fig. 2. TA-718 As Cast.
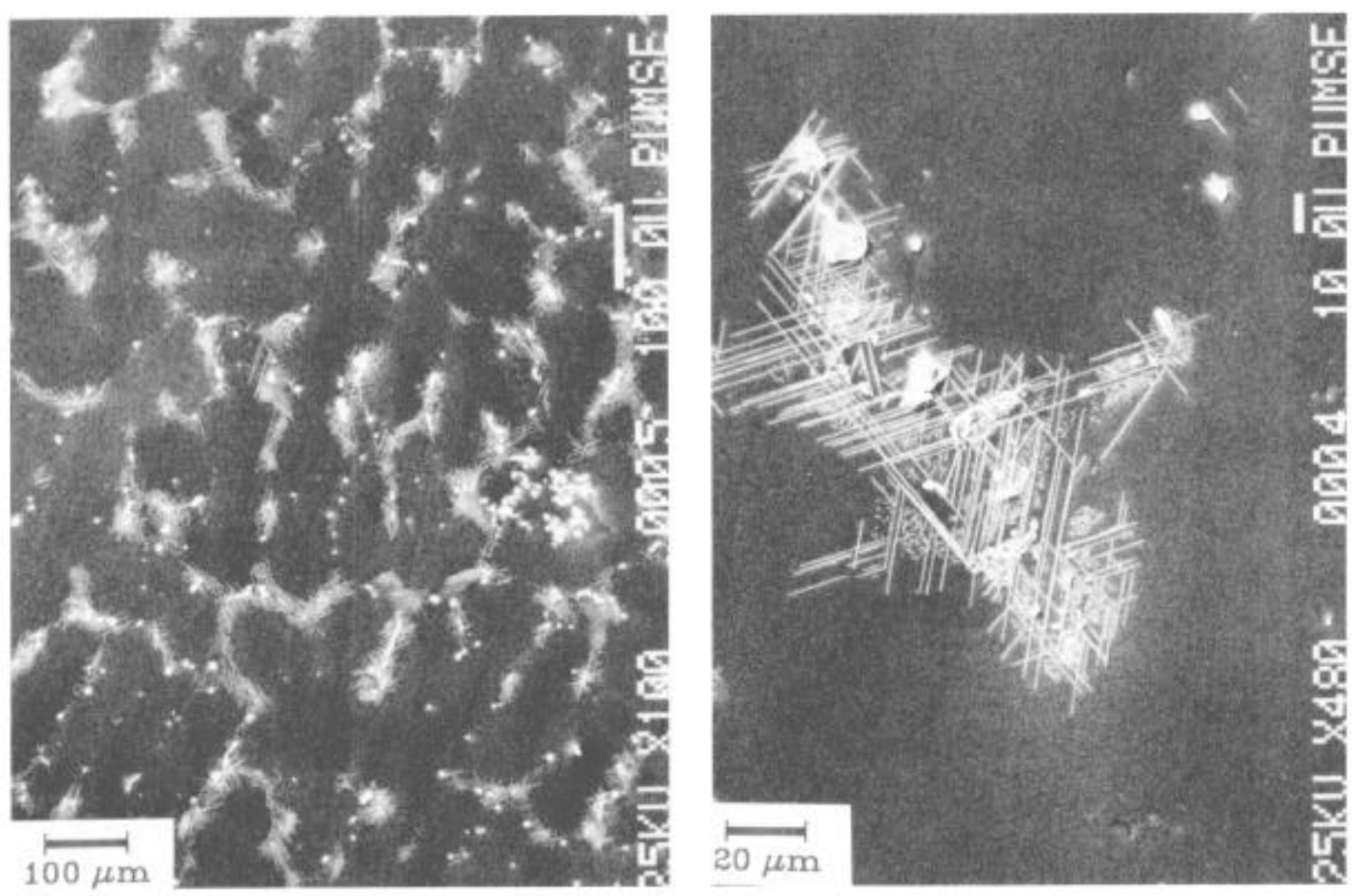

Fig. 3. Delta Phase $1900^{\circ} \mathrm{F} / 10 \mathrm{hrs}$. 
X-ray diffraction patterns of residue extracted from the as-cast material confirm the presence of an MC phase, Laves phase, and $\gamma^{\prime \prime}$ phase. Lattice parameter measurements and EDAX analyses of the extracted residue show the MC phase to contain predominately $\mathrm{Ta}$ with lesser amounts of $\mathrm{Ti}$. $\mathrm{Ta}, \mathrm{Ti}, \mathrm{Fe}, \mathrm{Cr}$, and $\mathrm{Ni}$ were detected by EDAX in the Laves phase while $\mathrm{Ta}, \mathrm{Ti}$, and Ni were detected in the $\gamma^{\prime \prime}$ residue. The $\gamma^{\prime \prime}$ phase was extracted using the $15 \% \mathrm{HCl}$ and $85 \%$ Methanol solution.

\section{Time-Temperature Study}

When exposed 10 hours at $1900^{\circ} \mathrm{F}$, plates of $\delta$ phase form as seen in Figure 3 . Within the plate areas a fine disk shaped structure is present. After $2000^{\circ} \mathrm{F}$ for 1 hour, the MC and Laves distribution have undergone little change, but the amount of $\delta$ decreases and the disk shaped phase disappears, Figure 4.

The MC and Laves phases are increasingly solutioned by the application of higher temperatures and/or longer times. Figure 5 shows the amount of $\mathrm{MC}$ present after $2050^{\circ} \mathrm{F}$ for 1,3 , and 20 hours of heat treatment. As samples are heat treated at higher temperatures, a reduction is observed in $\mathrm{MC}$ carbies in both size and quantity.

\section{$\underline{\text { Residual Segregation Study }}$}

The samples given the 4 hour heat treatments at 2000,2050 , and $2150^{\circ} \mathrm{F}$ were given a $1600^{\circ} \mathrm{F} / 1$ hour tag heat treatment to precipitate $\gamma^{\prime \prime}$ in areas of high $\mathrm{Ta}$ and Ti content. Figure 6 shows the effects of the 4 hour heat treatments on homogenization. Even after the $2150^{\circ} \mathrm{F} \mathrm{F} / 4$ hour heat treatment, the original solidification pattern is visible indicating that residual segregation remains after this heat treatment.

\section{Mechanical Property Results}

The results of the mechanical properties are given in Table 2. Room temperature tensile values of over $155 \mathrm{Ksi}$ show that the strength of TA 718 is as good as alloy 718 and far above the GE specification for tensile properties. Heat treatment $B$ produces a smaller drop in YS than Heat Treatment $A$ and an ultimate tensile strength of $130 \mathrm{Ksi}$ at $1300^{\circ} \mathrm{F}$ and $1200^{\circ} \mathrm{F}$ indicates that TA 718 retains its strength at higher temperatures than that of alloy 718.

The stress-rupture life at $1300^{\circ} \mathrm{F}$ is only a few hours for both heat treatments, but the $1200^{\circ} \mathrm{F}$ life of TA 718 ranged from 30 to 140 hours which easily meets the GE specification for cast alloy 718 . Such wide scatter is common in alloys like 718 and is expected in TA 718.

Structural studies were carried out on the broken test bars in order to understand the structural response of the TA 718 to post HIP heat treatments. Figure 8 shows the structures produced by $A$ and $B$ heat treatments. It is apparent that different thermal treatments can produce different responses in TA 718 and the beat treatments selected for the mechanical test program are not necessarily optimum for TA 718. Additional thermal treatments on solutioned TA 718 samples show that the $\gamma^{\prime \prime}$ phase precipitates as the major phase at a temperature of $1850^{\circ} \mathrm{F}$ without $\delta$ plate phase precipitation. 


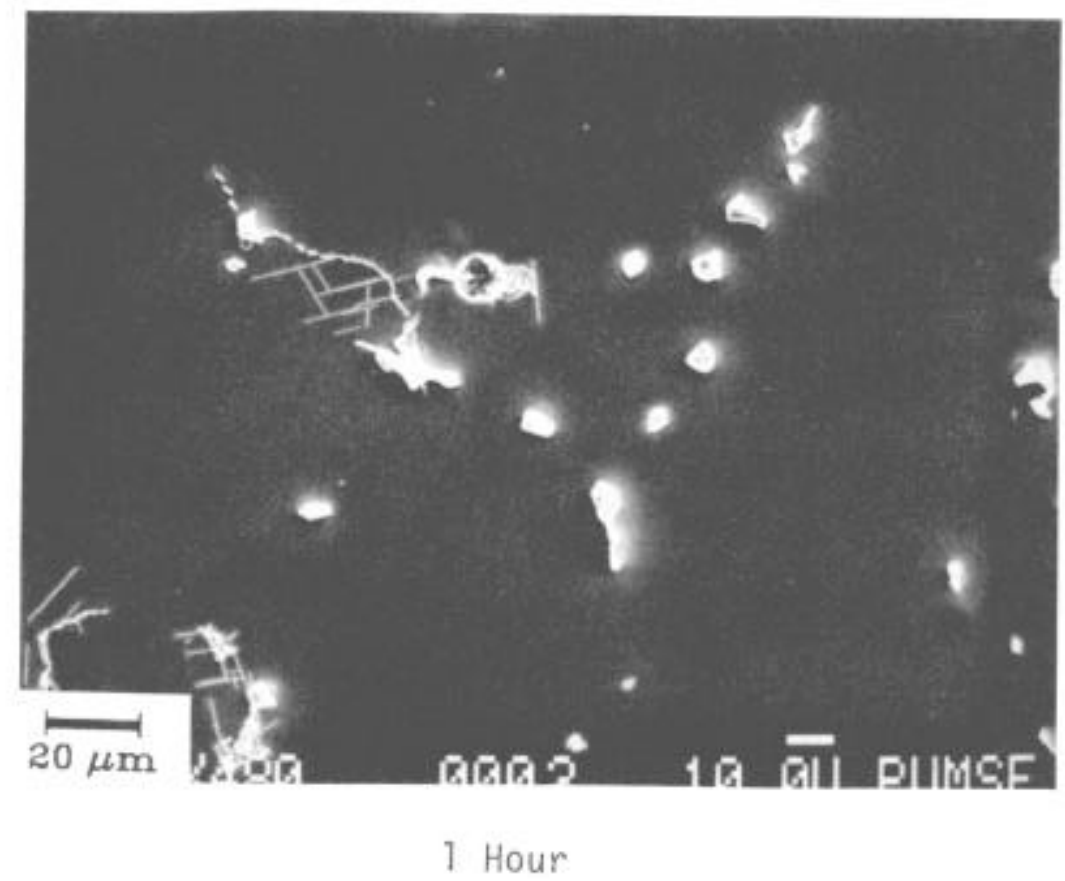

Fig. 4. Phase Stability a $2000^{\circ} \mathrm{F}$.

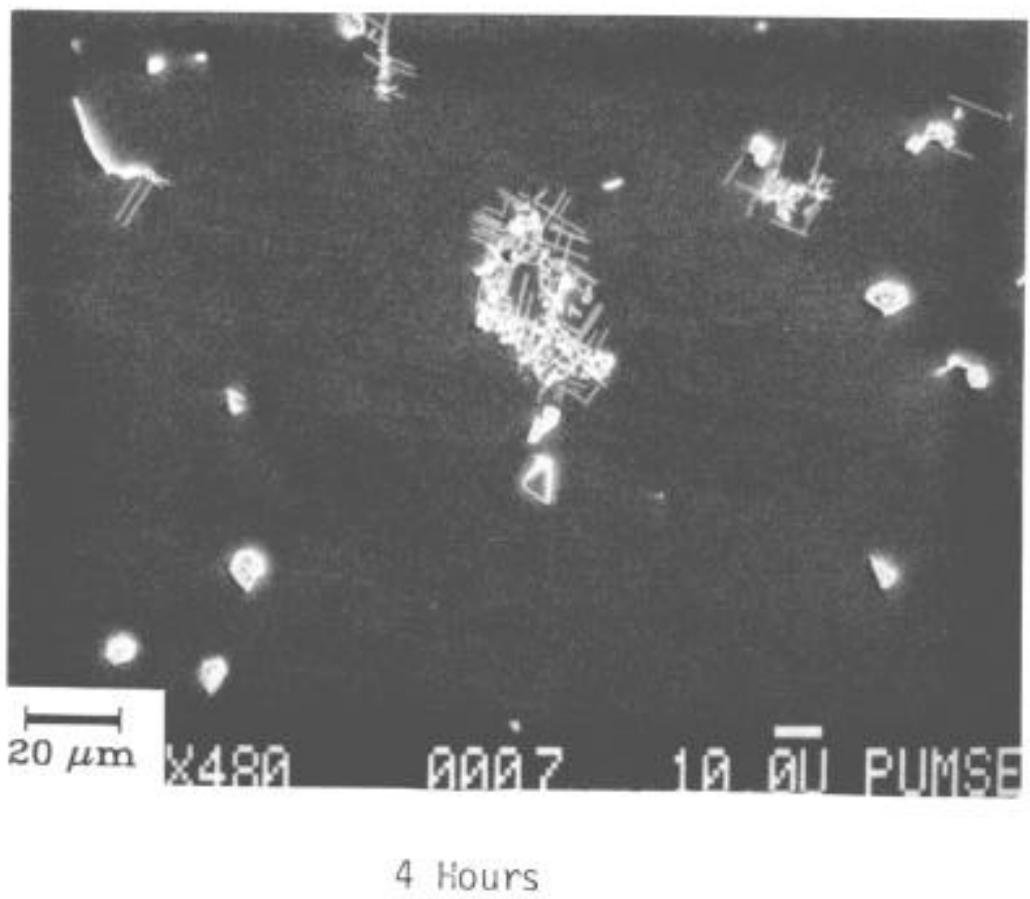




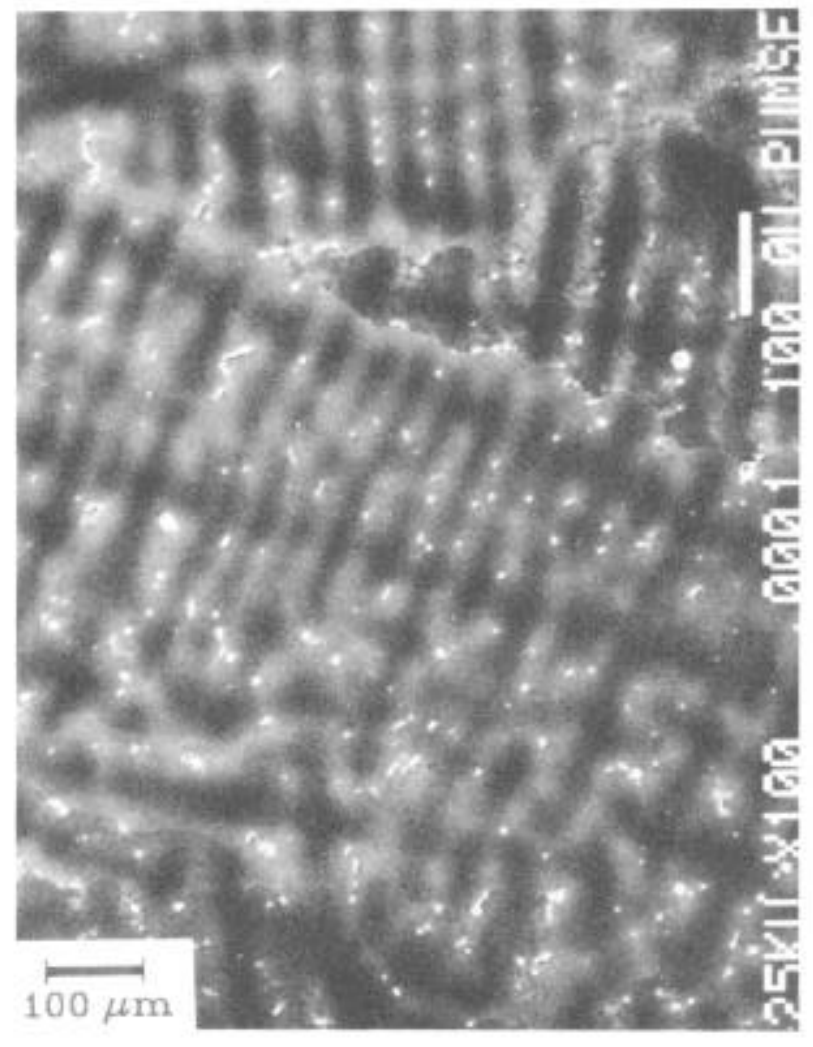

$2000^{\circ} \mathrm{F} / 4 \mathrm{~h}+1600^{\circ} \mathrm{F} / 1 \mathrm{~h}$

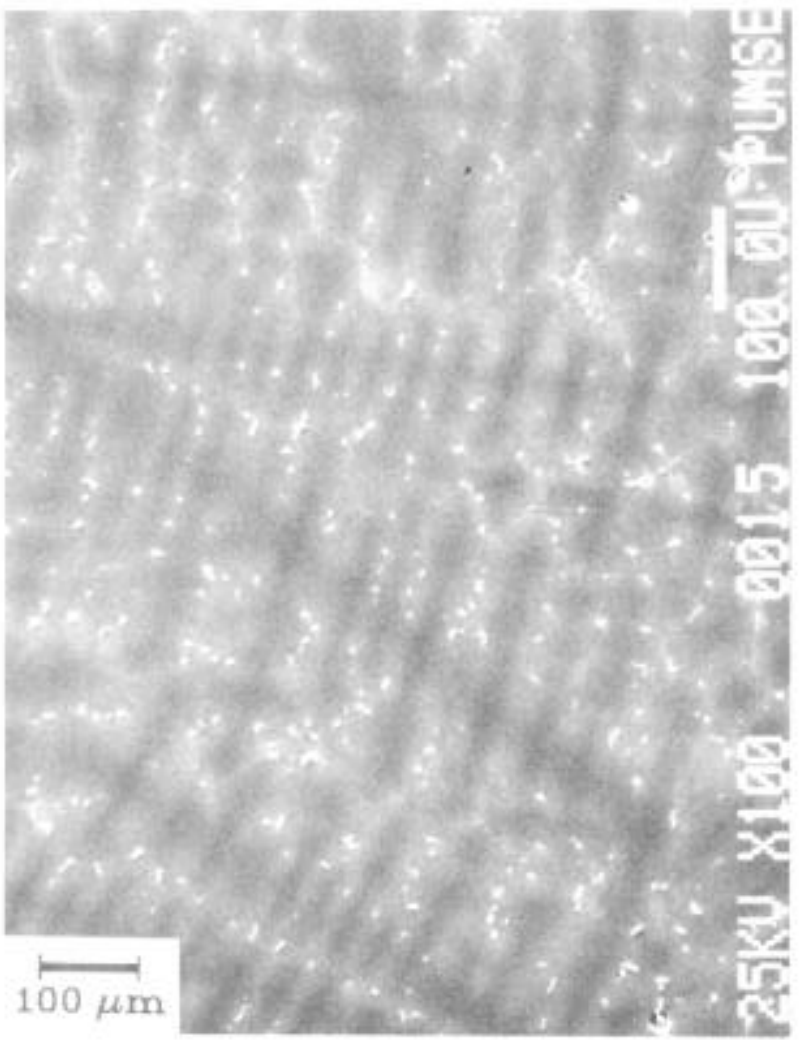

$2050^{\circ} \mathrm{F} / 4 \mathrm{~h}+1600^{\circ} \mathrm{F} / 1 \mathrm{~h}$

Fig. 5. Segregation Pattern after Heat Treatment.

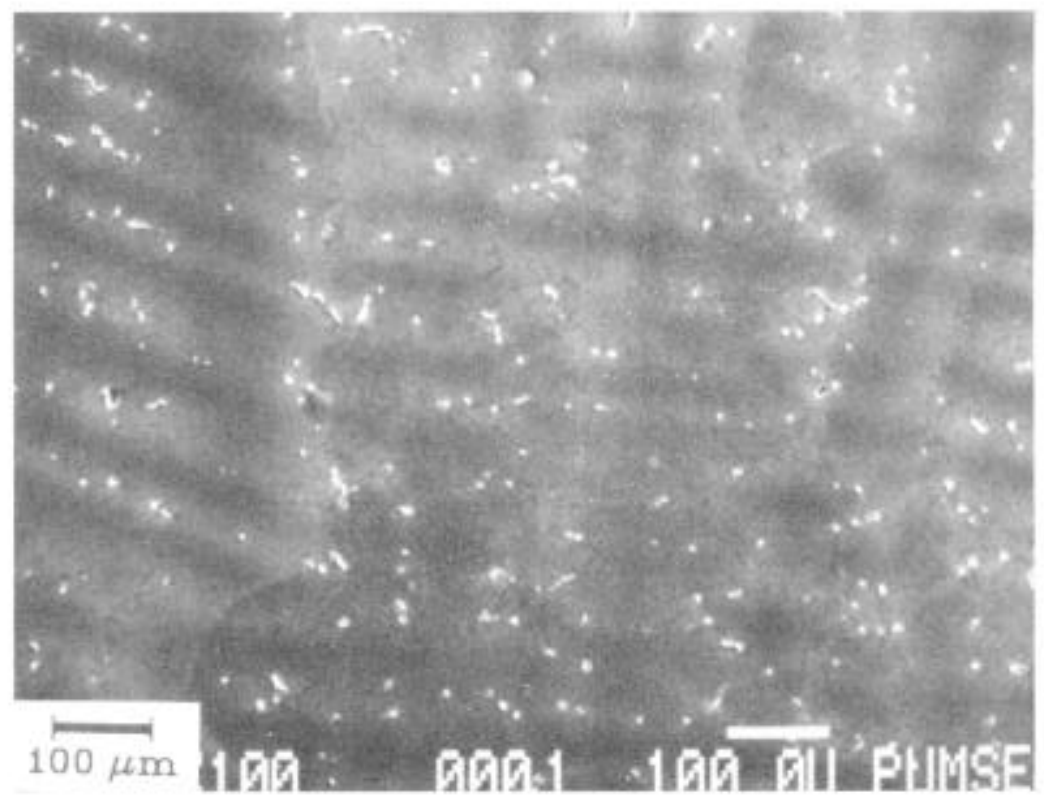

$2150^{\circ} \mathrm{F} / 4 \mathrm{~h}+1600^{\circ} \mathrm{F} / 1 \mathrm{~h}$ 

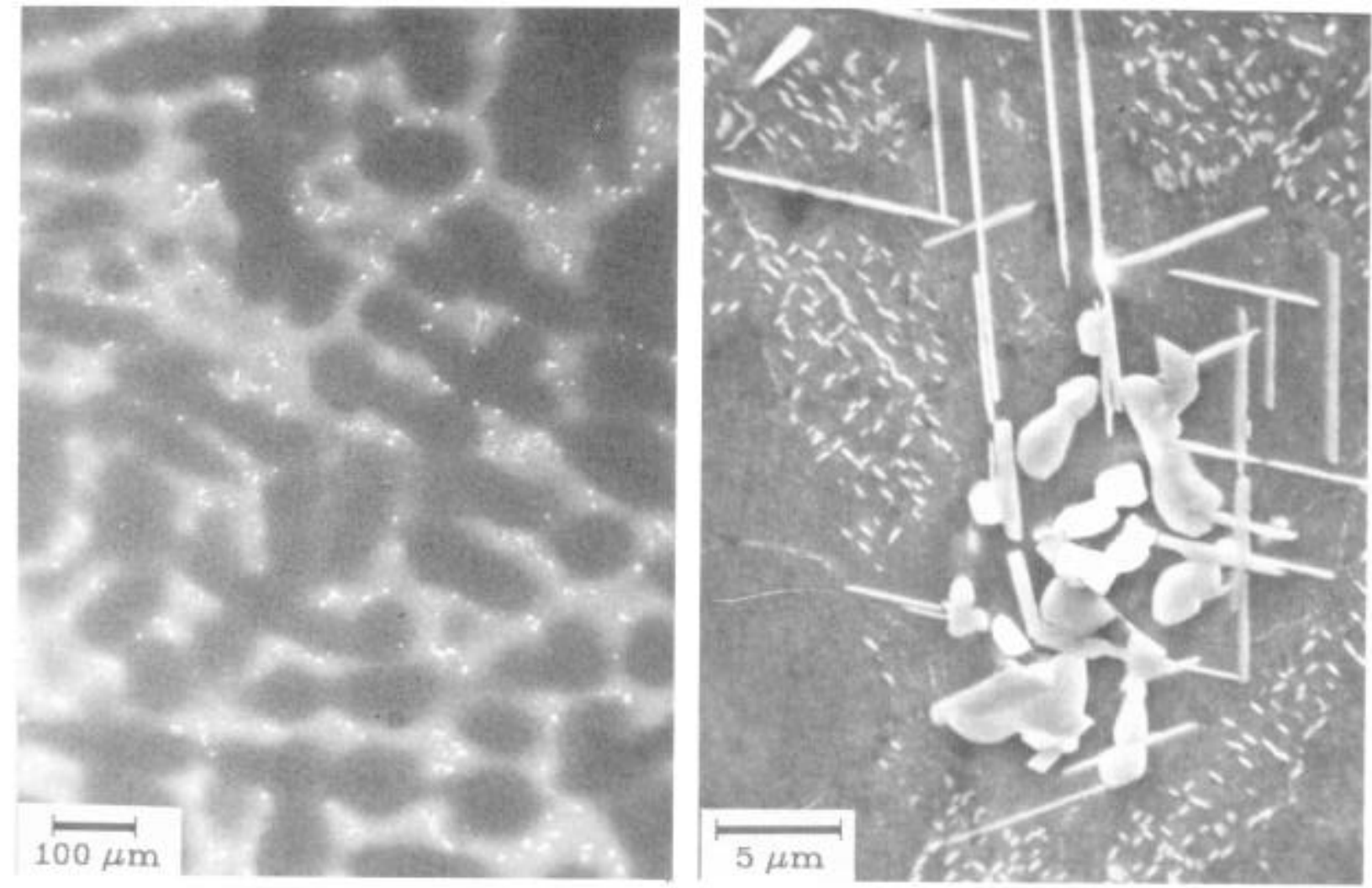

Heat Treatment A.

Fig. 6 .
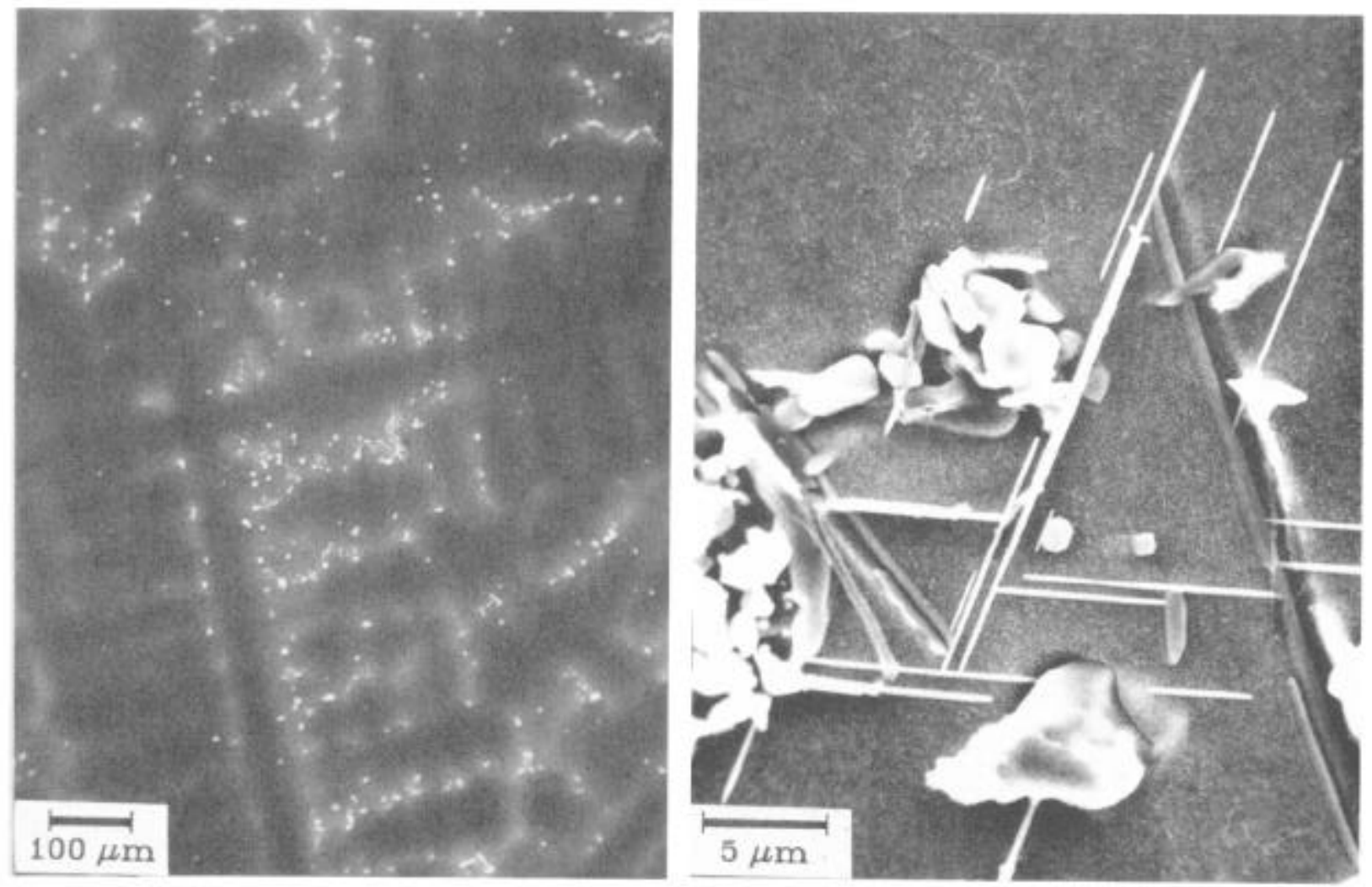

Heat Treatment B 


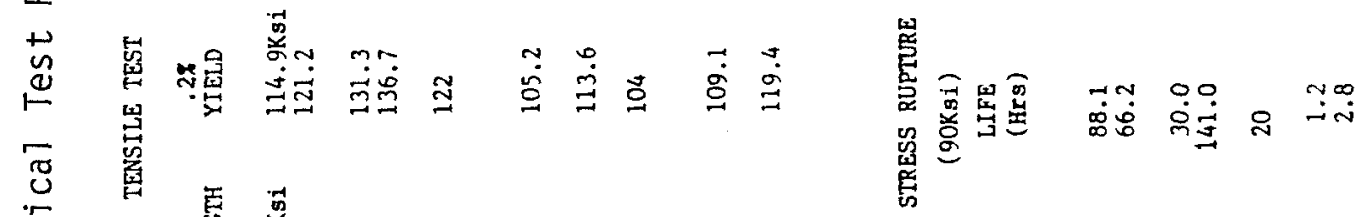

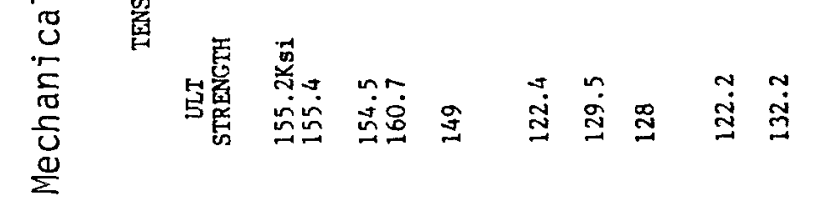

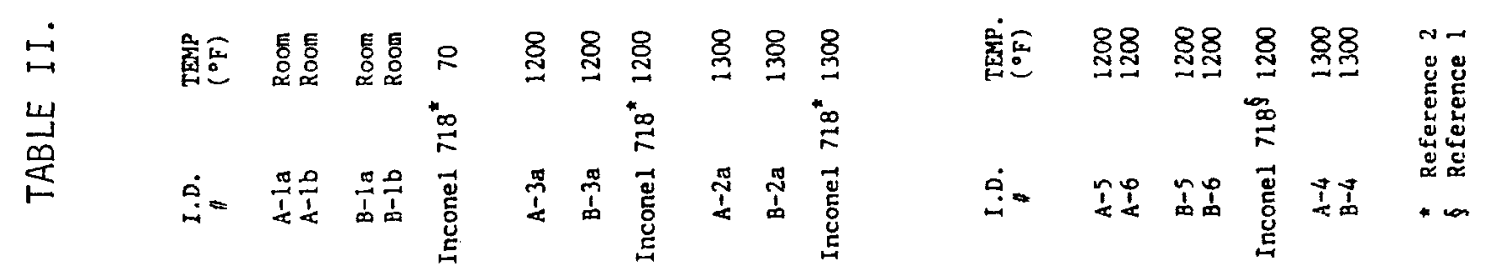

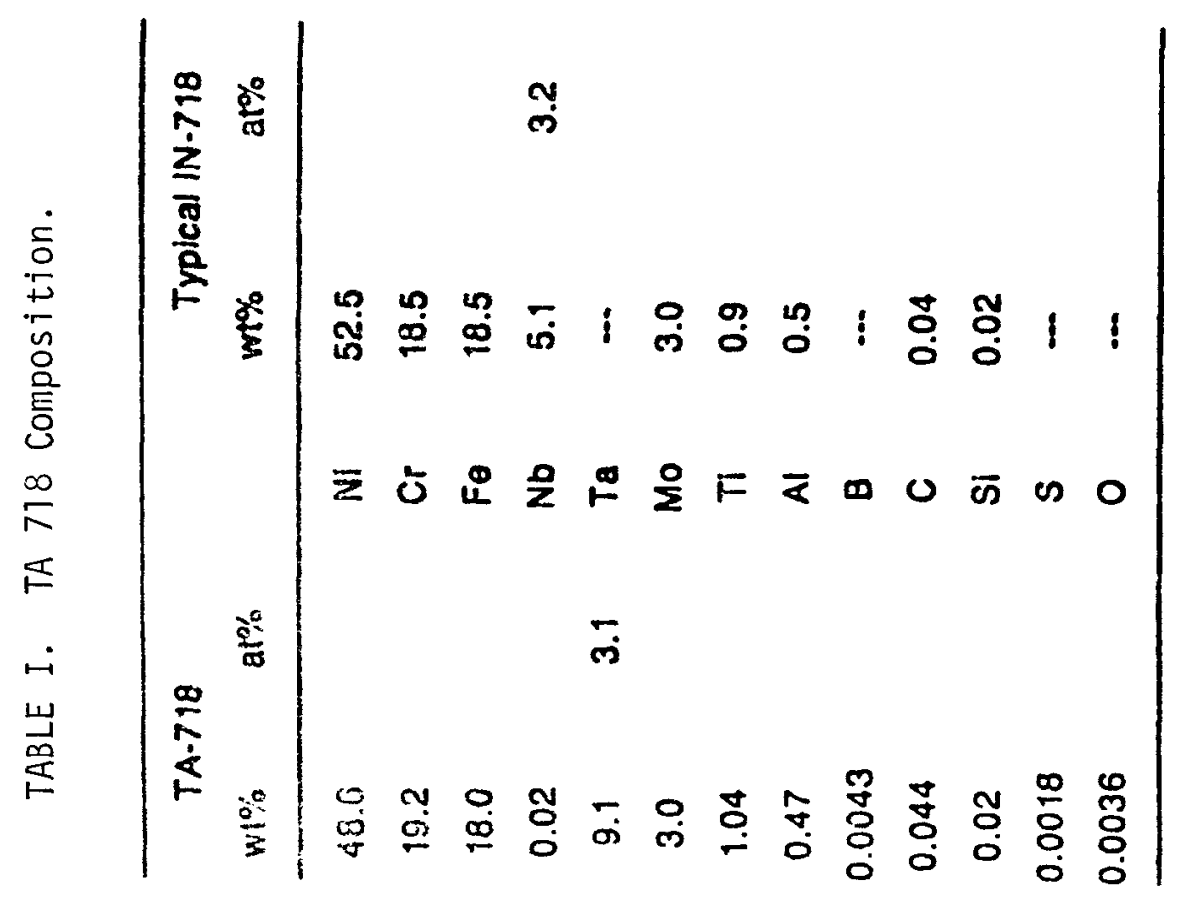

